\title{
THE TREATMENT OF SCOLIOSIS
}

\author{
F. J. HEDDLN. B.SC.. M.B., B.(il. (W+1FS). F.R.C.S. (EN(i.). F.R.C.S. (EUIN.)

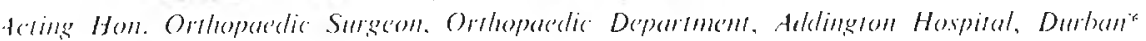

$\boldsymbol{J}$ ()HN Cobb of Ancriä, recently stalced in a lecture in London, that in order lo treal scoliosis. 'You don'l hatre to be crazy bul il sure helps"! In recent years. however, the manalement, although still controversial. has gradually prosessed along certain sinc and definitc lines. This has been due, in particular. co the development of accurale measurement of the curves by the method of Ferguson. ' later moditied by cobb:- spinal fusion as a method of treating scoliosis by Hibbs:- the use of a correcting lumbuckle jackel by Risser" and, linally the establishment of an aceuralte prognosis in idiopaltherice scollosis by Ponsetl and Fricdman."

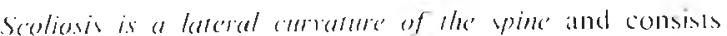
of 2-4 curtes. The commonest patlerm is the triple corve with a primalry or major culve in the middle. and i wo secondary or compensatory curves, ome above and onc below which detelop later in order io keep) the head direcily abow the pelvis. The matjor cure undergoes secondary changes. consisting of lixed rotation of the botics of the cortebrate so batl the spinous processes are rotalled to the comeatsity of the curve. and of wedging of the vertebrac on the concalse side. In the secondary curves rotation is much less marked and does not develop uncil much later (See tigs. I and 4.) ()her less common pallerens maly consist of 2 or 4 curses (sec below).

\section{Climical E.taminartion}

Casce of scoliosis alle bes! kealt with in at special clime so that adequate time cian be given to a detialed history and examinalion of eich calse. It is useful to record the lindings on a special form. The history should include the age of onset of the scoliosis, past illnesses (particularly poliomyelitis), the rapidity of progress of the curve, and whether lhere is any family history of scoliosis. The examination should be conducled with the child standing and the back should be examined in crest and bending positions. Details of the deformity should be recorded. such ats elevittion of the shoulder. prominems scapula. list of spine to one side. prominem fank erease and prominent hip. The apex of the major curve should be defined clinically with the child bending forward.

A complete muscle sharting should be performed, and the heiglot. weight and leg lenglhs recorded. The chest deformily should be noted and the vital calpacity of the lungs estimated. Finally a calreful search should be made for the caferent-lait matis on the skin found in newrotibromatosis, and clinicial photographs are laken for record purposes.

\section{X-rar Examination}

This consists of rouline films tatken on 17 14 inch platles. These are AP elect and supine of the whole spine. and also a lateral of the spine on the first visit of the patient. Bemding fitme are taken with the pallient bending first to the right and then to the left to ketermine the rigidity of the curves. In the paralytic curve after poliomyclitis, a tilt film is also laken (sce below).

The angles of the curves are measured and recorded. The limit of each eurve is distinguished by noling that. whereas in the primitry curve the dise is widened on one side, in the curve above or below it is widemed on lle opposite side. Al calch junction there is a neutral disc equal in widh on both sides. Lines atre drawn parallel to the lower border of the lowest wertebri and the upner border of the highest rercubra of each culve. From these lines perpendiculits alle erected, and the angles at which lhese meet alle the angles of the curres. The degree of wedging and rolation of the rertebrat is also noted. The results should be recorded on the special Scoliosis Chatrt.

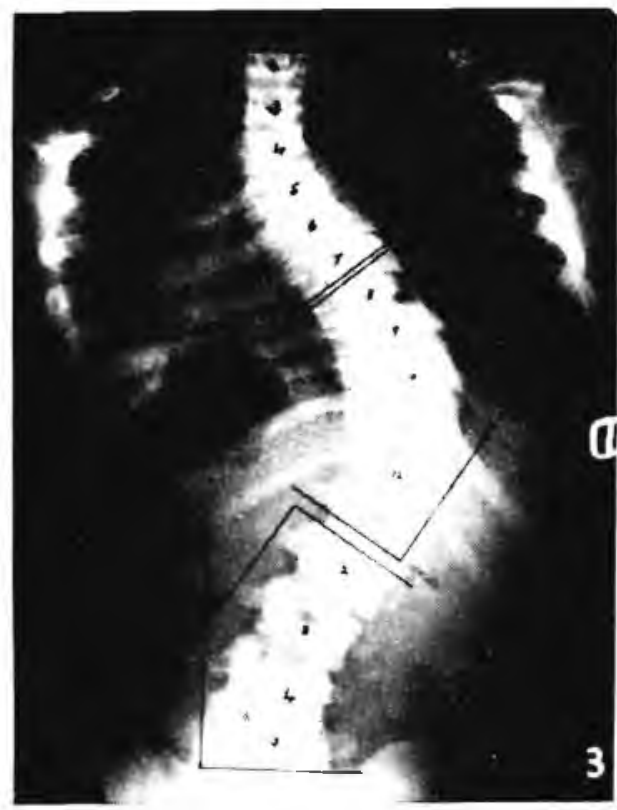

Figure 1.

A thoraco-lumbar idiopathic curre. 18- LI 71 (major curve) with upper sccondary curve, $12-1739$, and lower secondary curse, L.2-S1 35 .

Finally, whe child should be sech every 3 months. of later 6 months, for clinical exammalion and $X$-ray, until spinal growh has ceased and there is no further increase of the curve

CLASSIIC IIOX BY AIIOLOGY

The atetiology of the calse must now be accuralcly determined. In this paper the subject is comsidered in accordance with the following atetiologicall classilication:

A. Fancriomal

I. Postural

2. Compensillory

B. Sinncural

I. Idiopathic Scoliosis. 1.e. scollows an which the exalct aetiology is not honwn, consitules $80-90^{\circ}$ of all cilses.

2. Posi-poliomyelis $5-10^{\circ}$,

3. Neurotibiomatosis 2"

4. Congenital cutses less thatr 2" 


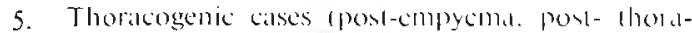
coplatsty) less thatn ?".

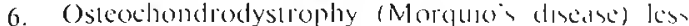
hatll I".

7. Frichrich's Alaxiat less lhall I" "

8. Spastic Parallysis and Rateds lery late

\section{A. Functional}

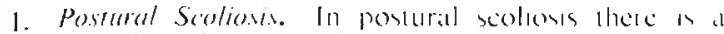
mild single lialcral curve, which desappears on surpemsen or on bencling forwald. Rotallon of the velabrate does nor occui, and the curve does not change mto a strucletal one.

2. Comprasuror Scoliosis is due to a shoul leg or to deformily of the hip ioint. It hows lwo cums whoul rotation, commencing all the level of the lumbo-sckral joint. Il does not progress and enly riacly, 11 eres. becomes a fixed structural curce.

\section{B. Structural}

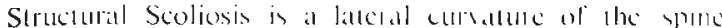
rwith rotation of the silebrike

\section{Kliopallic Scolionsis}

The malural history and prognose of the curve late been described by Ponseli and Filedmann." of Amelicil. and James of london." and ale of the utmol mportance in treatment. The higher the slle of the promelly curse and the earliel ils onsel. ble worse in the progmons. The onsel may be all any age in childhood

Riwer's sign is useful in the prognows It as sald lo be positive when the iliac apophyse appears an the radtograph all the way round the crests. From the anterior to the pousterior superior spines. This comcres wath the fuslon of the vertebral cpiphyses, following which, as there is no furlher

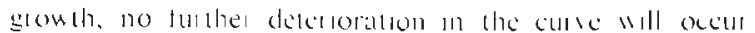

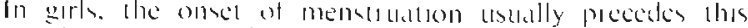
yen by a few momlins

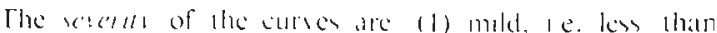

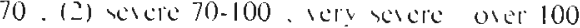



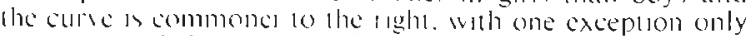
(sec (11) (111) below)

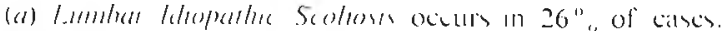

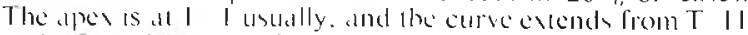
to L. 3. 9/".. are mild and the deformoly is slighe beciluse no rob, are insoled and the shoulders reman level. The

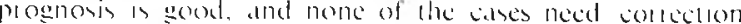

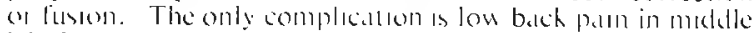

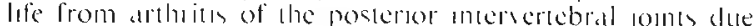
lo their exlleme rolalion

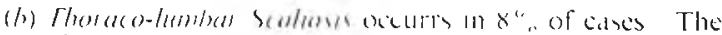

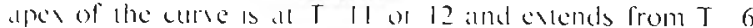

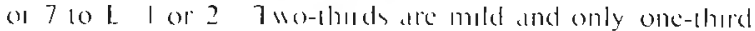

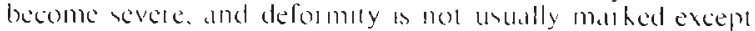

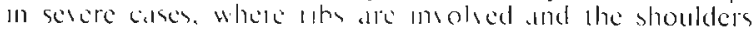

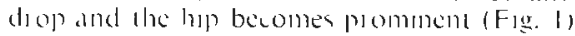

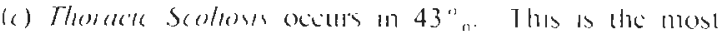
mportant geoup. for an these cases the curves progress

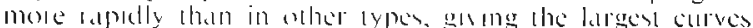
and prodtring the wors defommes The apex of lae

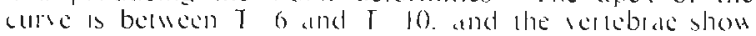

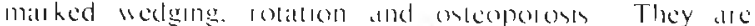

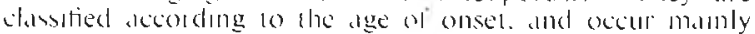
in the 3 persods of rapud gramilh

(1) The adolescent guoup. commencing after the age of 10 ycials 1210

(II) The ; of 5 and 8 years $\left(5^{\prime}\right.$,.) The catser an groups (i)

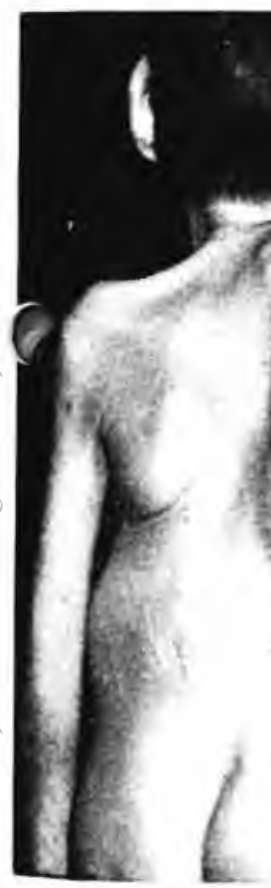

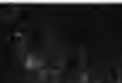
(1)

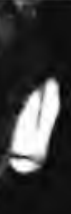

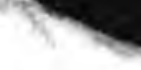

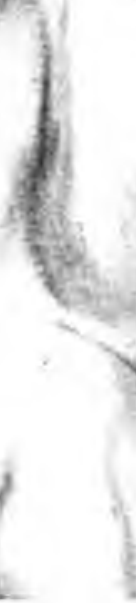

Figure 2.

Thoracic type paralytic scoliosis.

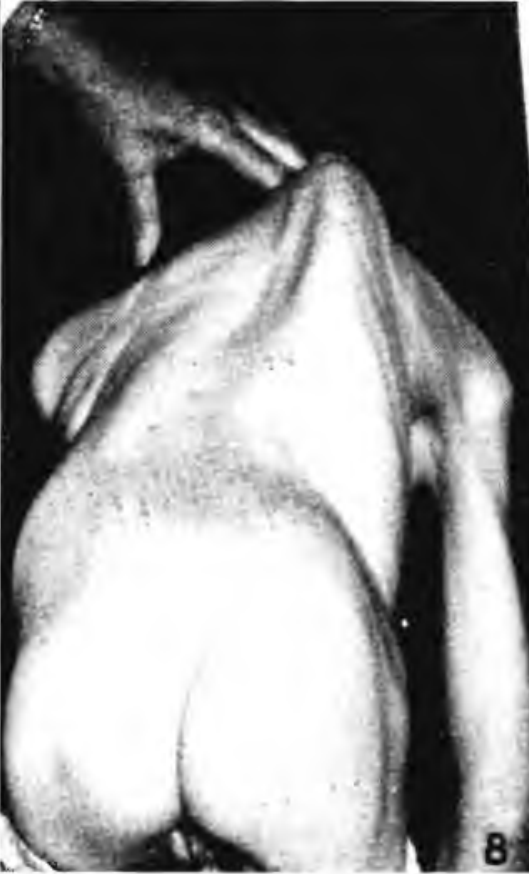

Figure 3.

Same case showing the "racor back" tspe of deformits due to rib rotation.

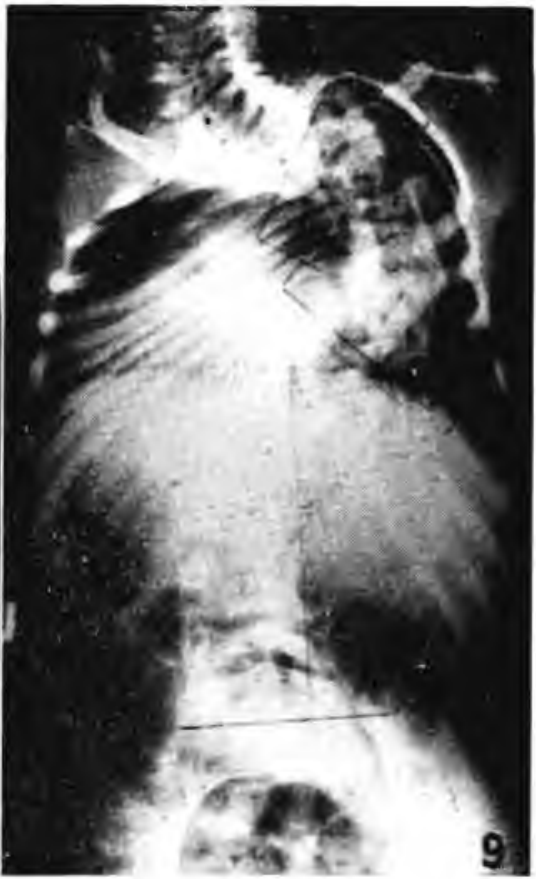

Figure 4.

Same case X-ra! curve 13 - 10 measuring 104 . 
and (ii) are commoner in girls and the curves are mainly to the right in both groups. The prognosis is bad; $60 \%$ of the adolescent cases and $85 \%$ of the juvenile develop severe curves.

(iii) The infantile thoracic group commences before 3 years of age $(17 \%)$. It is commoner in boys and the curve is more often to the left, making this a distinct pattern from the previous thoracic curves. The deformity is severe, rotation occurs early, and over $90 \%$ of cases are severe by the age of 10 years. The prognosis is very bad in the majority of cases; although in a few the condition remains stationary or disappears, in the majority it progresses steadily.

(d) Combined Thoracic and Lumbar Scoliosis occurs in $23 \%$. This combines the characteristics of both lumbar and thoracic scoliosis, and has 4 curves - 2 primary in the middle with rotation, and 2 secondary. The upper primary curve is usually from T. 6 to T. 10 , and the lower primary from T. 11 to L. 4. The two curves keep in step and balance each other, and the deformity is slight, for the shoulders remain level and the hips are covered. The prognosis is good.

\section{Paralytic Scoliosis ${ }^{9}$}

Scoliosis is common in a growing child after an attack of poliomyelitis with paralysis of the trunk muscles. There are two main groups (Fig. 5).

(a) Firstly severe symmetrical paralysis, which causes a collapsing spine, as the spine is unstable in the erect position but does not give a severe curve. It is due to the force of gravity. (b) Secondly, and more commonly, a curve develops from asymmetrical weakness of the trunk muscles plus the force of gravity, the convexity developing on the weaker side. The muscles which cause the scoliosis are the intercostals, the lateral abdominals and the quadratus lumborum. Even moderate inequality in these muscles on the two sides will produce a definite curve. A scoliosis may develop soon after the attack of poliomyelitis, or it may be delayed 5-10 years; so a careful watch must always be kept on the spine. The erector spinae, shoulder muscles, anterior abdominals and leg muscles do not cause scoliosis, although a contracture of the tensor fascia lata may cause pelvic tilting.

The curve patterns have some similarity to idiopathic scoliosis, but their prognosis is different (Fig. 6).

The Lumbar (Apex at L. 1-L. 2) and Thoraco-lumbar (Apex T. II or T. 12) are due to weakness of the lateral abdominals and quadratus lumborum muscles, and the Thoracic are due to the additional weakness of the lower intercostals (Figs. 2, 3, 4). These curves may progress and cause severe deformity, but they can be corrected surgically.

High Thoracic curves starting at C. 1 or C. 2 are due to paralysis of the intercostals. This can be demonstrated by a cine-film, by the decrease of movement of the ribs on the convex side, and by their more vertical position. The head is stepped to one side and the rotated ribs make the trapezius prominent, causing severe deformity. This curve is very difficult or impossible to correct and has the worst prognosis of all types of paralytic scoliosis.

Quadruple curves may occur with double primary curves in opposite directions and compensatory curves above and below, and the primaries may not balance each other as in the idiopathic variety.

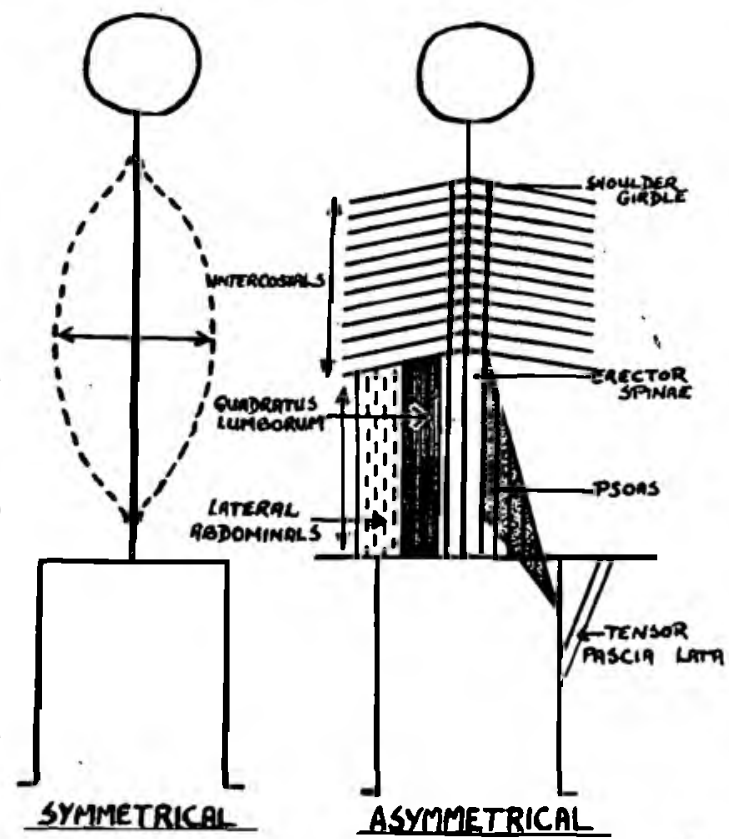

5

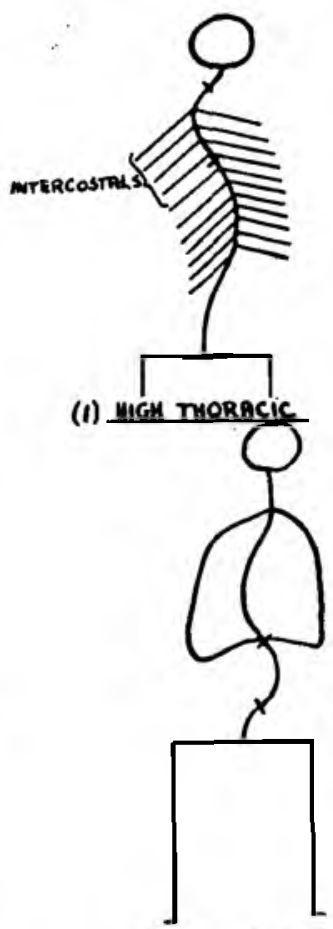

(4) Lumar

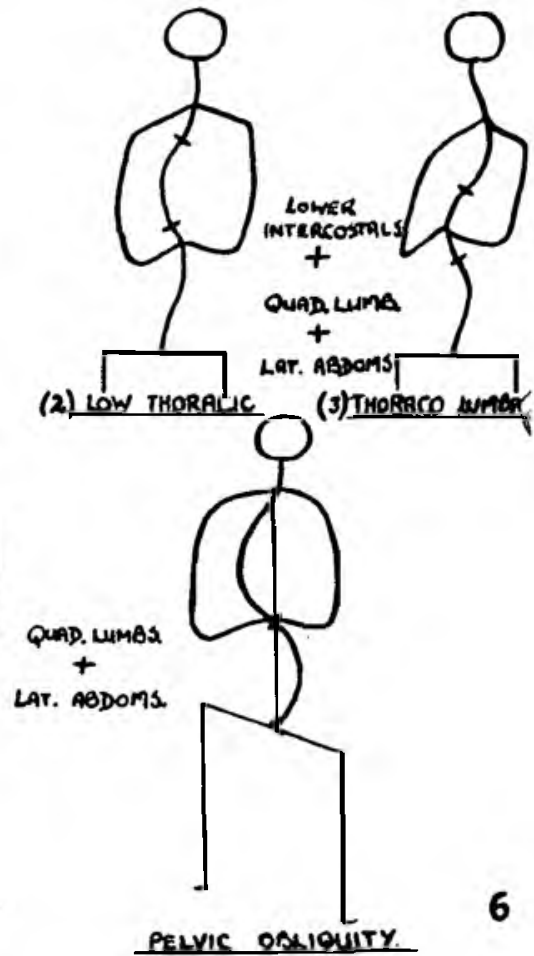

Figure 6.

Curve patterns in paralytic scoliosis due to asymetrical involvement of muscle groups.
Diagram showing the two main types of paralytic curve (see text). 
Pelvic Obliquity may be caused by contracture of the hip abductors and the tensor fasciae latae, paralysis of the lateral abdominals and quadratus lumborum, or a combination of them, and may be associated with a short marked lumbar curve.

The paralytic curve differs in appearance from the idiopathic and is typically a long C-curve with secondary compensatory curves. No accurate prognosis can be given in paralytic curves, owing to the difficulty in accurate charting of the affected muscles, but the earlier the onset and the higher the curves (as in idiopathic) and the greater the muscle imbalance, the worse the prognosis. However, unlike the idiopathic variety, the lumbar and thoraco-lumbar curves may cause great deformity.

\section{Neurofibromatosis}

A number of cases of neurofibromatosis develop scoliosis. The typical cases develop a short, sharp, acute angulating curve with wedging of vertebrae in the thoracic region. They all progress rapidly, causing severe deformity, and have the worst prognosis of any kind of scoliosis. Рaraplegia may be a complication in severe cases.

\section{Congenital}

Many types of abnormality may occur in the spine, such as hemi-vertebra, fused vertebra, spina bifida. The degree of scoliosis varies from mild to severe, as one hemi-vertebra may cancel out another. Nearly all double curves (except compensatory) are congenital. Prognosis based on X-rays is often impossible, and the curves have to be watched carefully.

\section{Kypho-scoliosis ${ }^{10}$}

In structural scoliosis, although there is often an apparent kyphosis due to the hump caused by rib rotation, there is no actual alteration in the anterior-posterior direction of the vertebrae. However, very occasionally a true kyphosis is associated with a structural lateral curvature, when the condition is called kypho-scoliosis.

\section{TREATMENT OF SCOLIOSIS}

\section{A. Conservative Treatment}

1. Physiotherapy. A great deal of time and expense has been wasted in unnecessary treatment of scoliosis.

In paralytic scoliosis following poliomyelitis, it is of value to treat the weakened muscles by active exercises, as is carried out in limb paralysis, for the first 18 months. In an extensive follow-up of cases treated by physiotherapy it has been shown by Sharrard of London, in recent years, that muscle exercises have very little value in paralytic scoliosis, and that where there are asymmetrical groups of muscles paralysed, it is impossible to balance them by uni-lateral exercises.

In other types of scoliosis, especially the idiopathic, exercises whilst being of assistance in improving posture and breathing, have unfortunately no affect on the progress of the scoliosis.

2. Correcting plaster beds and splints may be used in infants, such as the Merch-Jansen bed, or the Dennis Browne metal night splint, but neither is of use in older children.

3. Plaster iackets and spinal supports in older children should be avoided as far as possible, as they are only an encumbrance and fail to control the progress of the deformity. There are two exceptions, however:

Firstly in a case where there is a rapidly progressing curve and the patient is too young to operate on, the Milwaukee Brace of Blount ${ }^{11}$ is of great value and will control the curve or slow down the rate of increase. Constant distraction of the spine combined with local pressure is obtained by means of a moulded leather pelvic support connected to occipital and chin pieces by extensible anterior and posterior uprights. A lateral pressure pad exerts pressure at the apex of the curve.
Secondly, in paralytic curves, when there is a collapsing type of curve without severe scoliosis, the patient in unable to sit up or stand, and the posterior spinal support with axillary crutches is necessary.

\section{B. Operative Treatment: Correction and Fusion}

The operative correction consists of correction and fusion of the major curve in a turnbuckle plaster jacket.

1. In Idiopathic Scoliosis, if the curve pattern and the age of onset are considered together, an accurate prognosis is possible. Correction and fusion should be carried out for the prevention of future deformity; and, as there are no symptoms in the idiopathic variety, the indications are mainly cosmetic. Occasionally where there are severe chest deformities and a low vital capacity operation is indicated to prevent pulmonary and cardiovascular complications. Less than $5 \%$ of cases of idiopathic scoliosis need operation, and these consist almost entirely of the thoracic group, where the prognosis is bad and severe deformity may develop if untreated. When the deformity is established, the depression of the shoulder and prominence of the hip can be corrected, but the projecting rib hump remains. In a mature child a curve of $65-80^{\circ}$ is ugly enough to warrant correction on clinical appearance alone. In a young patient before deformity is serious, correction is relatively easy and more complete, but it is advisable to delay operation until the age of approximately 10 years to avoid interference with spinal growth or the production of a kyphosis, although in severe rapidly-progressing curves earlier operation may be necessary. Thus in a curve of $55-60^{\circ}$ in a child of 10 years, correction and fusion would be indicated because of the bad prognosis.

2. In Paralytc curves $50 \%$ need operation. These curves are unstable and the treatment of the stability of the spine is more important than the correction of the deformity.

(a) In a fail collapsing spine scoliosis may develop late owing to gravity and may also be indicated in order to give a rigid link between the trunk and leg. In the latter type, before fusion to the sacrum is performed it is important to establish that the patient has active hip flexors present. If these are absent and the patient has to rely on the lateral abdominals to elevate the pelvis in order to swing the leg clear of the groung in walking, fusion of the spine to the sacrum will stop all walking. However, in a severe case with flail legs and spine, fusion to the sacrum may be indicated to make the patient a good sitter, and allow working at a desk without back support.

(b) Unstable paralytic curves need correction and fusion firstly if the curve is rapidly progressing in a young case and the prognosis is bad because of severe muscle imbalance (the fusion should be left until the child is as old as possible but it may have to be done at an early age if there is rapid deterioration); and secondly if symptoms are produced such as pain from back fatigue or ribs pressing in the pelvis or if there is displacement of abdominal viscera or kinking of the ureter. Unstable curves become stabilized after cessation of growth of the spine, i.e. after the appearance of $R$ isser's sign, and in some cases this may occur even earlier. In stable curves, further deterioration does not occur, or if it does, is only slight, and operation is for cosmetic reasons.

(c) In high thoracic paralytic curve correction is difficult, and fusion should be carried out early, before deformity arises.

(d) The lumbar and thoraco-lumbar paralytic curves, unlike the idiopathic, may become very severe and cause great deformity, but they are easy to correct, although difficult to fuse successfully.

(e) Pelvic obliquity. Soft-tissue stripping of the contracted lateral abdominal muscles on the concave side, from the crest of the ilium, may be necessary in severe 


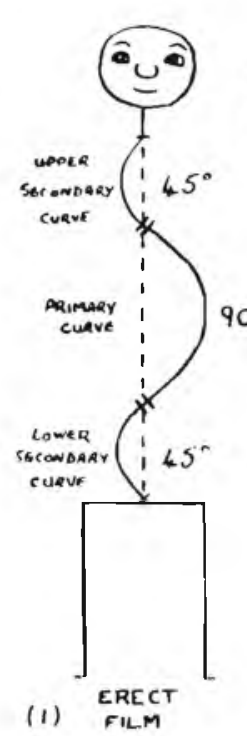

(2) BENDING

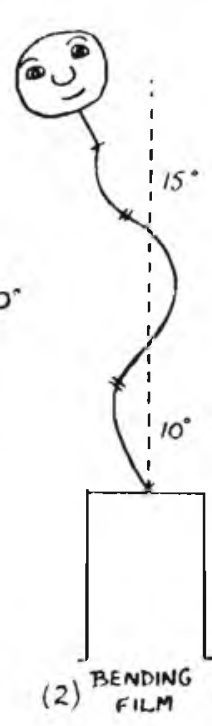

(3)

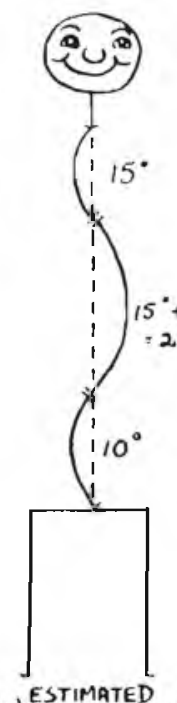

CORRECTION

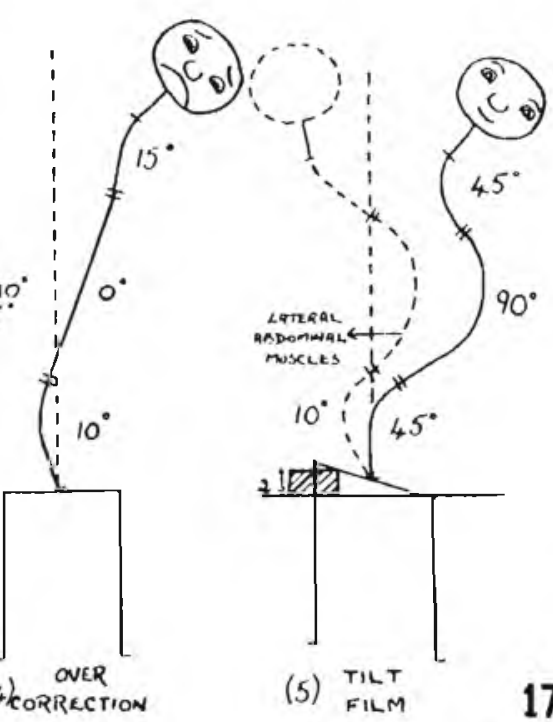

(5) TILT
FILM

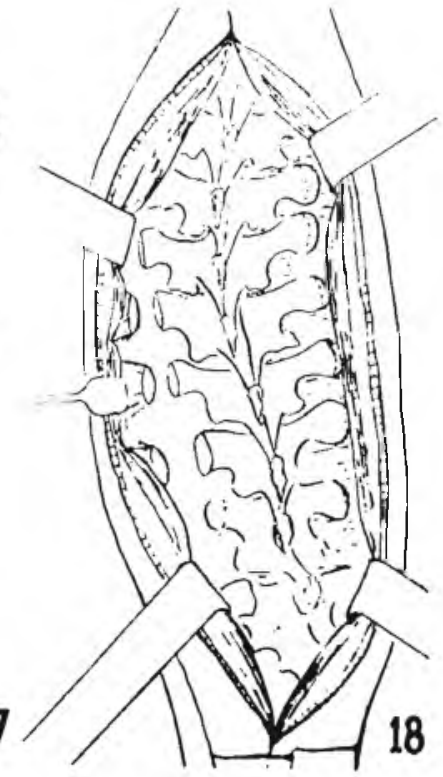

Figure 8 .

Figure 7.

Diagram illustrating the use of bending and tilt films in estimating the theoretical amount and correction possible.

piralytic curves, before correction caln be obtained in a plaster jacket. The weaker muscles on the convex side may be reinforced by strips of the fascia latal from the iliac crest to the yth or 10 th rib by Meyer's method, ${ }^{2}$ or by the more recent method of Clark, in which the tensor fasciale latiac and the ilio-libial band is turned upward and atlached to the 9 th rib to give a dynamic reinforcement.



Figure 9.

Risser jacket. showing correction of curve by a turnbucklc.

Figure 10.

Risser jacket: correction has been completed, and a window cut over spine for operation.
3. Nearly all cases of newofihromarosis need operation becaluse of their rapidly developing thoracic curves.

4. Congenital Scoliosis. Usually conservative treatment is adequate. but occisionally correction and fusion is indicalted. Alternatively, stapling of the thoracic spine of cxcision of a hemi-vericbrac in the lumbar region has been attempted, but these methods are not generally advised.

5. Krohorexoliosis, In kypho-scoliosis early correction and fusion is indicaled, becaluse of the very bad prognosis, imd here there is no feal of producing a lordosis by calrly fusion.

\section{ME1HOI) OI CORBICTION AND FUSION}

This consists of fusion of the whote of the primary curve or curves. Before correction and fusion can be attempled the Mohility of the colves must be determined in order to ascertain the degree 10 which it is possible to correct the primary curve, since it is essential to matian the head over the pelvis so als to keep the patient well balaneed. This is determined from the bending tilm laken originally. and determines the amount of stiffness in the sccondary or compensitlory curves (Fig. 7).

If. for example the paltient has a 90 primary curve and a 45 upper and a 45 lower secondary curve. The bending filn may show that those (wo curves correct to only 15 and 10 respectively in bending, owing to stitfness. The primary curve can then only be corrected to $15+10$ i.e. 25 if the head is to be kept over the pelvis. If the spine is over-corrected, for eximple to the straight position, as hats beell done in the past. the result may be disastrous: the patient will look like the leaning lower of Pisis.

In a case of paralyic scoliosis, a till film with a 3 -inch block under the bullock on the convex side of the lower secondaly curve must also be done to be sure that the spine can be held 10 the full extent of its mobility, ats shown in the bending filnt. by the weilk lateral abdominal muscles 
(in this particular case held over to a position $10^{\circ}$ short of the vertical). If this cannot be done the fusion must include all the secondary curves down to the sacrum.

\section{Technique of Correction}

Correction of the primary curve is achieved by means of a Risser turnbuckle jacket (Fig. 9). Felt pads are applied over the bony prominences and over the apex of the curve to prevent undue pressure on the skin. The jacket is applied standing, with head traction by means of a halter to straighten out the secondary curves, and also to give a good fit for the jacket. It is a full spinal jacket with shoulder straps; the leg on the side of the primary curve is included down to the knee. Anterior and posterior hinges are placed on the side of the convexity, well lateral to and opposite the apex of the curve, and the turnbuckle screw is placed on the concave side. When the plaster is dry it is cut transversally at the apex of the curve. Correction by elongating the turnbuckle is rapid at first but will later become slower. No discomfort should be produced at any time. A paralytic curve may correct in a few weeks, but an idiopathic may take up to 10 weeks, and in old patients full correction of the promary curve of the estimated degree may not be possible. When the end-point of correction has been obtained it will be found that the patient tends to slip out of the jacket, instead of being further corrected. Complications are rare with careful nursing, apart from minor pressure sores.

When correction is finished the gap in the plaster is filled in, hinges and turnbuckle are removed, and a window is cut over the spine for operation (Fig. 10). A metal marker is placed over one spinous process and an X-ray is taken to determine the vertebral level.

The distraction jacket designed by Stagnara, of Lyons, is useful in correcting the high paralytic thoracic curves, which the Risser jacket fails to correct. It is also used in the combined lumbar and thoracic curve with a double primary curve, and also for correcting kypho-scoliosis. However, there are more risks of pressure sores with this type of jacket than a Risser.

The localizer body cast has been developed by Risser in recent years as an alternative to the turnbuckle jacket. ${ }^{14}$ This is a plaster cast applied on a special frame with head and pelvic traction, whilst localised pressure is exerted postero-laterally over the rib angulation, forcing the apex of the curve under the ends of the curve and thereby producing correction. It may be used for conservative treatment or for correction and spinal fusion, and its main advantage is early ambulation.

\section{Technique of Fusion}

The method of fusion advocated is that which has been developed by J. I. P. James at the Royal National Orthopaedic Hospital, London. The mechanical force which, after fusion, tends to cause relapse of the curve is a lateral angulating one, and so the aim is to produce a broad, wide fusion area of the whole of the primary curve to combat this. This entails a complete lateral exposure of the spine is far as the apophyses of the transverse processes and meticulous removal of all intervening soft tissue. Profuse haemorrhage results, and it is essential to begin blood transfusion before the operation starts, or severe shock from blood loss may ensue.

If possible the operation is done in one stage, and in a young patient 8 or 9 vertebra can be fused at one step, but occasionally 2 or even 3 stages are necessary. A large supply of refrigerated stored bone must be available. Boiled bone may be used as an alternative, but it is believed, though this is not yet known for certain, that consolidation of the graft may then take longer than when fresh bone is used.

The operation area is towelled off and the site of the original metal marker is preserverd on the skin by means of methylene blue, to act as an indicator of the level of spinal processes. A straight skin incision is used from top to bottom of the curve, and the skin flaps are undermined with diathermy. Subperiosteal stripping of the spinous processes, laminae and transverse processes is performed, and the apophyses of the transverse processes are tipped off, to allow the spinal muscles to be retracted as far lateral as possible (Fig. 8). The spinous processes are then removed and the laminae and transverse prosesses are completely decorticated with a rougine. In older children a power-driven burr may be used instead, and this diminishes shock.

A deep, wide raw bed is left and this is covered with a large mass of bone chips from the bone bank.

Finally silver clips are placed on the spinous processes above and below the fusion as a radiographic guide, and the wound is closed in layers.

The patient is kept recumbent for 6 months in the $R$ isser jacket, and then is allowed up in a polythene jacket. Alternatively, a Milwaukee brace may be used, particularly if relapse is feared, as in high thoracic cases.

One year after the operation bending films of the primary curve are taken to exclude a pseudo-arthrosis and, if satisfactory, all support is abandoned.

Two other operative techniques have been introduced recently but, although they may be indicated in certain cases, as yet they are not recommended in routine work:

Firstly, Allen, ${ }^{15}$ of Birmingham, uses a jack which is inserted between the transverse processes on the concave side; the jack is opened, correcting the curve; and finally spinal fusion is performed without post-operative plaster fixation.

Secondly, Roaf, ${ }^{16}$ of Oswestry, corrects the apex of the curve by removing a wedge of bone from the convexity of the curve, including laminae, pedicles, transverse processes and adjacent portions of two vertebral bodies and intervening disc.

\section{Results of Fusion}

The greater the curve, the greater is the force tending to cause relapse after operation. The average relapse following operation is about $25^{\circ}$. This is usually due to pseudoarthrosis of the graft, which occurs in about $10 \%$ of fusions or else to a too limited fusion of the primary curve. ${ }^{17}$ The preliminary results of firsion are encouraging, but final assessment of this method of treatment cannot yet be made in a large enough group of cases, until all these spines operated on have ceased to grow, but there is every indication that the present method of managing scoliosis will produce good results and prevent the development of the hideous deformities, which are still only too common.

\section{To Sunmarize the Treatment of Scoliosis. ${ }^{\mathrm{ts}}$}

I. Scoliosis should be dealt with in a special clinic where adequate facilities and time are available. The patients should be checked every 3-6 months until growth of the spine has ceased.

2. In idiopathic scoliosis $5 \%$ of the cases need early fusion and correction, mainly in the thoracic type at the age of 10 , in which the prognosis is bad.

3. Of paralytic curves $50 \%$ need operation because of instability, production of symptoms or deformity, and early fusion is specially indicated in the thoracic type.

4. Nearly all cases of neurofibromatosis need early operation, but this is only rarely necessary in scoliosis of the congenital type.

I wish to express my thanks to Mr. J. I. P. Jaines, of the Royal National Orthonaedic Hospital, London, for his help and encouragement, and to Mr. G. T. du Toit, of Johinnesburg, and Mr. R. C. J. Hill, of Durban, for allowing me to use their clinical cases. In addition I would like to express my thanks to the editor of $S$. African Medical Journal for his permission to reproduce the illustrations used in this article. 


\section{General}

\section{WORLD CONFEDERATION OF PHYSICAL THERAPY}

Copy of a letter received from Miss Neilson, Secretary of the World Confederation of Physical Therapy.

"As a result of a broadcast 1 gave on my return from East Africa, I have been able to put a completely paralysed polio patient in Nairobi in touch with a young man in England similarly placed. This latter young man (Paul Bates) now wishes to have additional contacts with people who are also completely paralysed, and I am writing to ask whether you know of any such patient in your country with whom I could put Paul Bates in touch.

If any of your members knows of such a patient would they please send his name and address to Mrs. Levy, I05, Acacia Road, Blackheath, Johannesburg. She will forward it to Miss Neilson.

At a C.E.C. meeting held in Johannesburg on August 13th, a special welcome was extended to $M$ iss Bodoano and Miss Savin both teachers of Physiotherapy who have recently come out to Pretoria Physiotherapy School from Britain. We all wish them every success and happiness in this country.

\section{APOLOGY.}

The Article "Some uses of Heat and Exercise in the Obstetric and Gynaecological Unit" which appeared in the June issue should have been attributed to Dr. D. M. Lithgow, Specialist in Gynaecology at EDENDALE Non-European Hospital, not Edenvale Non-European Hospital.

\section{JOURNALS RECEIVED}

1. "Physiotherapy" Chartered Society of Physiotherapy, London.

2. S.A. Medical Journal.

3. Medical Proceedings-S.A. Journal for advancement of Medical Science.

4. Heilgymnastiek Massage en Physiotechniek-Nederlandsch Tijdschrift.

5. Sjukgymnasten-Kvinnliga Sjukgymnasters Riksförbund.

6. Tidsskrift for Dankse Fysioterapeuter

7. Revue des Kinésithérapeutes-Organe de la Féderation des Masseurs-Kinésithérapeutes de Francè et de L'Unoin Française.

8. Krankengymnastik-Offizielles organ des Zentralverbandes Krankengymnastik. E.V.

9. Le Journal de Kinésithérapie-Cercle d'Études Kinésithérapiques.

10. The Physical Therapy Review-American Physical Therapy Association.

11. World Veteran-World Veterans Federation.

The above Journals may be borrowed on request from the editor, before being filed for reference.

\section{In Alnumaram}

It is with sorrow and regret we have to report that Miss Clara Hopson died in Durban on July 4th, 1958, at the age of 85 years.

Miss Clara Hopson trained, it is believed, at Kings College Hospital, London, during the first World War, having previously done a nursing training.

She passed the Examination of Incorporated Society of Trained Masseuses in massage in June 1916, her Electrical examination in December, 1917. In 1921 she became a member of the then recently formed Chartered Society of Massage and Medical Gymnastics and received her L.E.T. Certificate in March, 1930.

Miss Hopson registered with the S.A. Medical and Dental Council in 1949.

Miss Clara Hopson's life has been bound closely with that of the I.S.T.M., C.S.M.M.G. and S.A.S.P. since their inception.

During her very busy life, she treated soldiers in the 1914-1918 War and came to this country during that period and for the purpose of treating the wounded of that War.

In 1922 she joined the S.A.S.P. in Durban. The Society was first founded in Durban in 1921. Later she became a Life Member.

Miss Hopson was in charge of the Physiotherapy Department at Addington Hospital until she retired at the age of 55 years. She then commenced private practice and learned to drive a car. She continued this work and to drive a car until as recently as five years ago.

During the last year she was responsible for collecting the funds from Physiotherapists to send Brian Blankenberg overseas.

Miss Hopson lived for many years at the Y.W.C.A. in Durban, and was loved and respected by all who came in contact with her. She will be sadly missed by all of us who knew her in Durban.

\section{MR. CHRISTOPHER GELL.}

The sympathy of the Society is extended to Mrs. Norah Gell on the death of her husband Christopher Gell in Port Elizabeth recently.

In spite of contracting polio in 1945 with severe generalised paralysis resulting in his spending most of his last 13 years in an iron lung, he found the courage and the will to live He married Norah Gell, M.C.S.P., Middlesex Hospital, London, who nursed him, besides continuing her practice after his illness. She taught him to type thus enabling him to carry on with his writing.

\section{Continued from pase 9}

\section{REFERENCES}

1. Ferguson, A. B. (1930): Sth Med, J. (Buham Ala.) 23, 116

2. Cobb, J. R. (1948): Outline for the Study of Scoliosis, American Academy of Orthopaedic Surgeons' Instructional Course Lectures, 5,261

3. Hibbs, R. A. (1924): J. Bone Jt. Surg., 6, 3

4. Hibbs, R. A., Risser, J. C. and Ferguson, A. B. (1931): lid., 13, 91

5. Risser, J. C. (1948): Important Practical Factors in the Treatment of Scoliosis, American Academy of Orthopaedic Surgeons' Instructional Course Lectu res, $5,248$.

6. Ponseti, I. V. and Friedman, B. (1950): J. Bone Jt. Surg., 32A, 381

7. James, J. 1. P. (1954): Ibid., 36B, 36 .

7. Idem (1951): Ibid., 33B, 399 .

9. Idem (1957): A nn. Roy. Coll. Surg. Vol. 2I-July 1957.

10. Idem (1955): J. Bone Jt. Surg., 37B, 414

ii. Blount, W. and Schmidt. The Milwaukee Scoliosis Brace. W. C. Campbell (1956): In Operative Orthopaedics. St. Louis: C. V. Mosby.

12. Mayer, L. (1944): J. Bone Jt. Surg., 26, 257.

13. Clark, J. M. P. and Anatol Axer (1956): loid., 58B. 475

14. Risser, J. C. (1955): The Application of Body Casts for the Correction of Scoliosis. Ame Application of Body Casts for the Correchin bo Scollosis. American Academy

15. Allan, F. G. (1955): J. Bone Jt. Surg., 37B, 92

16. Roaf, R. (1955): lbid., 37B, 97

17. James, J. i. P. (1957): Personal communication.

18. Hedden, F. J. (1958): I he Management of Scoliosis. South African Medical Journal, Vol. 32, No. 23, L. 582.

\footnotetext{
- Paper read at the Annual Meeting of the South African Orthopaedic Association, Durban 1956.

* Formerly Senior Registrar, the Royal National Orthopaedic Hospital and the Hospital for Sick Children, Great Ormond Street, London.
} 